\title{
Estudo de caso avaliativo da construção de um aterro controlado entre duas linhas ferroviárias no Estado do Maranhão
}

O presente trabalho faz uma análise de linhas ferroviárias da Companhia Ferroviária do Nordeste (CFN) e a Estrada de ferro Carajás (EFC). Onde o projeto visa absorver possíveis impactos de um descarrilhamento ferroviário, devido ao solo ser argiloso com características moles. Sabemos que construções sobre solos moles acarreta inúmeros problemas é representa um grande desafio em obras ferroviárias. Hoje há diversos tipos de esforços que possibilitam construir sobre esses tipos de solos. Nesse trabalho será determinado quais ensaios em laboratórios e ensaios de campo são necessários para fazer a caracterização granulométrica do mesmo, além de exposição de técnicas construtivas como a substituição de solos moles, aterro sobre sobrecargas temporárias, a implantação de drenos como medidas para evitar o processo de recalque, avaliando as possíveis etapas que devem ser investigadas no projeto para implantação de uma dessas técnicas.

Palavras-chave: Solos; Ensaios; Granulometria; Drenos.

\section{Evaluative case study of the construction of a controlled landfill between two railway lines in the state of Maranhão}

Or present trabalho faz uma analysis of linhas ferroviárias da Companhia Ferroviária do Nordeste (CFN) and Estrada de ferro Carajás (EFC). Onde or projeto visa to absorb possíveis impacts of a railroad decarrification, due to or only being argiloso with characteristics moles. We know that construções sobre sol moles carries many problems and represents a great challenge in railway works. Browse through various types of efforts that you can build on these types of solos. Nesse trabalho will be determined in six laboratories in the field and in the field only in order to determine the granulometric characterization of the mesmo, in addition to the exposition of construction techniques such as the replacement of single moles, terrarium over temporary overloads, to the implantation of temporary overloads, to the implantation of drains as measures to avoid or process of highlighting, endorsing as possíveis stages that should be investigated no project for the implementation of a technical gap.

Keywords: Soils; Essay; Granulometry; Drains.

Danielle Cristina dos Santos Lisboa (iD Centro Universitário Dom Bosco, Brasil http://lattes.cnpq.br/3350912872257730 http://orcid.org/0000-0001-8707-2442 daniellecristinaeng@gmail.com

Mayara Souza Gomes (iD

Centro Universitário Dom Bosco, Brasi http://lattes.cnpq.br/3105506268556273 http://orcid.org/ 0000-0001-5563-229X mayarabless@hotmail.com

\section{Lucas Nadler Rocha (iD}

Centro Universitário Dom Bosco, Brasil http://lattes.cnpq.br/8693441362635767 http://orcid.org/0000-0003-1424-2054 lucasnadlerrocha@hotmail.com

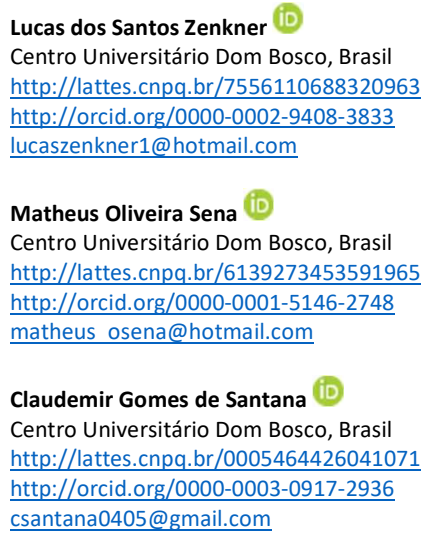

Renata Medeiros Lobo Muller (iD

Centro Universitário Dom Bosco, Brasil http://lattes.cnpq.br/2366742124450336 http://orcid.org/0000-0001-5202-837X renata.muller@undb.edu.br
Referencing this:

LISBOA, D. C. S.; GOMES, M. S.; ROCHA, L. N.; ZENkNER, L. S.; SENA, M. O.; SANTANA, C. G.; MULLER, R. M. L.. Estudo de caso avaliativo da construção de um aterro controlado entre duas linhas ferroviárias no Estado do Maranhão. Engineering Sciences, v.7, n.3, p.1-8, 2019. DOI: http://doi.org/10.6008/CBPC2318-3055.2019.003.0001 


\section{INTRODUÇÃO}

O solo é uma parte de extrema relevância para a construção, pois é sobre o mesmo que a edificação estará erguida e fixada. Sendo assim, é indispensável o estudo prévio deste, como também o estudo das possíveis alternativas cabíveis para determinada situação envolvendo-o sendo adotada a que se mostra mais viável entre elas. Nesse contexto, em algumas situações da construção civil é preciso construir sobre solos moles.

Para Cirone et al. (2017), problemas podem ser encontrados ao se construir sobre esse tipo de solo, pois o mesmo tem uma baixa capacidade de suporte, ao construir o aterro sobre solos moles o engenheiro deve saber lidar com problemas como recalque para que garanta que o aterro se encontre estável.

Para a implantação do sistema ferroviário é necessário também o reconhecimento geológico geotécnico considerando as diretrizes do projeto, devendo ser disposto um plano de sondagens e investigação do solo, sendo o número de sondagens e ensaios devem ser especificados para cada trecho do projeto (DNIT, 2015).

Para Nascimento (2008), para aterros ferroviários há uma grande dificuldade com problemas como o recalque de subleito que acontece a longo prazo isso decorre da falta de alinhamento correto da via permanente. Devendo-se ter cuidados na escolha da melhor técnica de execução quando há a implantação e duplicação de ferrovias em solos moles. Nesse contexto será proposto ensaios para análise de um sole mole na construção de um aterro entre duas linhas ferroviárias no Estado do Maranhão, sendo proposto ensaios para a caracterização do solo e reforços para a fundação.

\section{METODOLOGIA}

\section{Solos Moles}

Ao realizar análise do projeto o solo possui uma camada muito mole, tratando se um solo extremamente compressível, o que pode acarretar com problemas na construção do aterro. Para Lemos (2014), solos compressíveis são aqueles que sofrem uma significativa variação do seu volume quando está sobre a ação de alguma força, pressão que o faça comprimir. Para Machado (2012), o solo mole pode causar sérios problemas pois apresenta características como compressibilidade, baixa resistência e permeabilidade e baixa consistência.

\section{Recalque}

Para o processo de construção em solos moles diversos problemas podem ser encontrados dentre ele temos o recalque, de acordo com os autores Maragon (2018), citado por Nascimento (2008), os recalques são classificados como recalque imediato, recalque primário e recalque secundário. Recalque inicial é caracterizado por acontecer a partir do momento que o solo sofre solicitações.

Ainda segundo o autor o recalque primário está associado à expulsão da água dos vazios, e no caso dos solos argilosos merecem uma atenção especial, pois podem ocorrer em uma variação de tempo extensa, 
ou seja, podem não ser percebido de imediato, o que pode gerar recalque diferencial a certo prazo. Esse então é o principal critério da curva tempo x recalque: o recalque secundário pode prejudicar a estrutura, e é algo que pode ocorrer em um período de tempo não imediato. Portanto deve ser previsto por cálculo previamente. O último tipo, recalque secundário caracteriza-se por acontecer em um longo período de tempo, tempo suficiente para que a estrutura possa se adaptar. A seguir é possível observar a relação dos tipos do recalque com a variação de tempo na Figura 1.

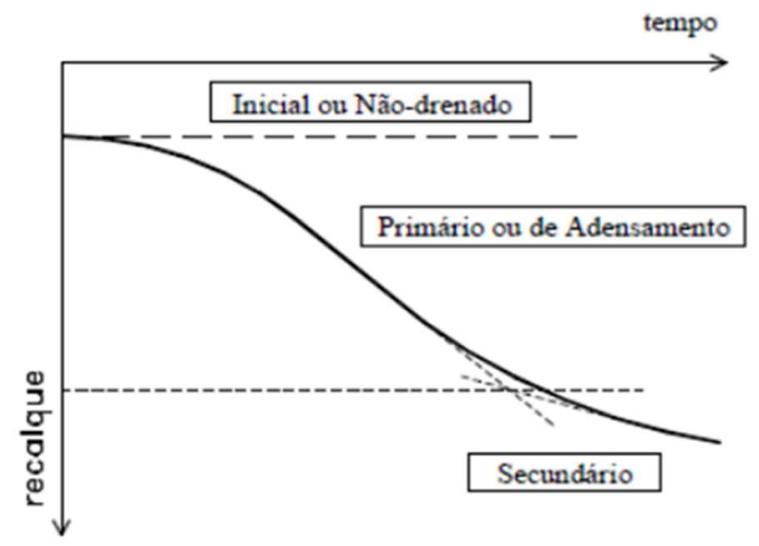

Figura 1: Relação do Tipo de recalque em função do tempo. Fonte: Maragon (2018).

Para análise desse tipo de solo é necessário realizar determinados ensaios para caraterização do solo realizados em laboratório e ensaios de campo, e determinar métodos construtivos para que o solo não sofra com o processo de recalque.

\section{Ensaios de caracterização física}

Os ensaios de caracterização física para análise desse solo temos o ensaio de granulometria que ocorre por peneiramento, por sedimentação, análise do limite de liquidez, limite de plasticidade, umidade natural e densidade relativa dos grãos ensaios de laboratório que caracteriza o solo disposto no projeto. 0 ensaio de granulometria por peneiramento para Morais (2015), ele é utilizado para determinação da curva granulométrica do solo, determinando uma porcentagem em peso obtendo uma faixa especifica para o tamanho dos grãos apresentando a massa seca total obtida no ensaio.

Para Sousa (2011), o limite de liquidez é considerado o teor de água que serve de divisa entre o comportamento fluido e moldável, permitindo fazer a classificação de solos finos determinando a plasticidade. O ensaio consiste com uma utilização de uma concha semiesférica denominada de Casa Grande, o aparelho possui um cortador de golpes o ensaio determina o número de golpes e recolhe uma porção do solo e determina o teor de água. O índice de plasticidade de acordo com Caputo (1988), ele é determinado utilizando o cálculo de porcentagem de umidade para que o solo comece o processo de faturamento quando se tenta molda-lo utiliza-se um cilindro com $3 \mathrm{~cm}$ de diâmetro com cerca de $10 \mathrm{~cm}$ de comprimento.

\section{Ensaios de Campo}

Diversos ensaios são utilizados para análise de solos moles os mais comuns de são o de palheta e piez 
cone para solos moles. Para a NBR 3124 (2018), retrata que o ensaio de palheta se utiliza para solos argilosos moles a rijos, saturados sendo usado para avaliar a resistência de solos em condições onde a drenagem é impossibilitada. Para Almeida (2010), o ensaio de palheta é utilizado para determinação da resistência drenada (Su) do solo mole a palheta e rotacionada constantemente por $6^{\circ}$ por minuto sofrendo influência de alguns fatores como atrito mecânico, a velocidade de rotação, heterogeneidade, amolgamento e anisotropia da argila.

\section{Métodos Construtivos sobre solos moles}

\section{Substituição de solos moles}

Uma das possíveis soluções para o projeto em questão como este possui um solo mole e compressível é a retirada do material existente e, posteriormente a substituição do mesmo por um material de maior qualidade que possa resistir aos carregamentos exigidos. A escavação para retirada do material deve seguir os parâmetros do projeto, isso caso seja viável realizar tal procedimento, levando em conta o custo para tal (ARTERIS, 2015).

No entanto, para tal procedimento são necessárias algumas ressalvas, sobre esse ponto Nascimento (2008) diz que em áreas urbanas sua utilização e frequentemente problemática, pois os taludes de baixa inclinação requerem que se avance muito sobre os terrenos vizinhos, podendo causar problemas com os proprietários dos mesmos.

Os grandes volumes de terraplenagem acima citados elevam sobremaneira os custos de empréstimo de aterro, já que este material e sempre mais oneroso nas áreas urbanas do que nas rurais. Além disso, existem as questões ambientais envolvidas na obtenção de jazidas de empréstimo para o material de aterro e locais de bota-fora para a argila mole (NASCIMENTO, 2008).

\section{Aterros sobre sobrecargas temporárias}

Para Nogueira (2010) é uma técnica que pode ser viabilizada em solos moles seu procedimento consiste na aplicação de sobrecargas de sobrecarga temporária em solos moles quando estes apresentam alta deformabilidade tendo como principal finalidade prevenir os recalques gerados pelos carregamentos frequentes que são gerados pela construção, ou seja, a sobrecarga tem como finalidade de adensar a camada compressível.

Nesse procedimento não é feita a retirada do solo mole, porém é realizado um aterro sobre esse material. Esse processo consiste em acelerar o processo de adensamento por meio de uma sobrecarga temporária. Posteriormente quando o recalque atingir estabilidade a sobrecarga é retirada (GAUI FILHO, 2017). Essa sobrecarga possui o valor que gira em torno de $1 / 4$ a $1 / 3$ do peso total do aterro. 0 intervalo de tempo em que será utilizada é verificado no local analisando o adensamento, além de ser prevista previamente por estudos (Departamento de Estruturas e Fundações - UERJ). 


\section{Drenos Verticais}

Essa se trata de mais uma maneira de acelerar o processo de adensamento. Tal alternativa pode ser associada, por exemplo, com a sobrecarga temporária, uma vez que ambas atuam com o mesmo fim: diminuir o tempo de adensamento do solo. Esse procedimento consiste basicamente na utilização de drenos verticais para diminuir as distâncias de drenagem, ou seja, a água irá percorrer um menor trajeto. Esse método não altera o valor final de recalque, mas acelera o processamento (GAUI FILHO, 2017).

Para Almeida (2010), aterros construídos com esse material que também são denominados de geodrenos e drenos fibroquímicos, consiste num núcleo de plástico com formato de canaleta, com um filtro geossintético envolto, inicialmente executa-se a camada drenante, logo em seguida crava-se os drenos e executa-se o corpo do aterro, ao ser cravado este é associado a sapata garantindo o seu engaste no fundo da camada. Na Figura 2 representa os detalhes de um aterro com a utilização de drenos verticais.

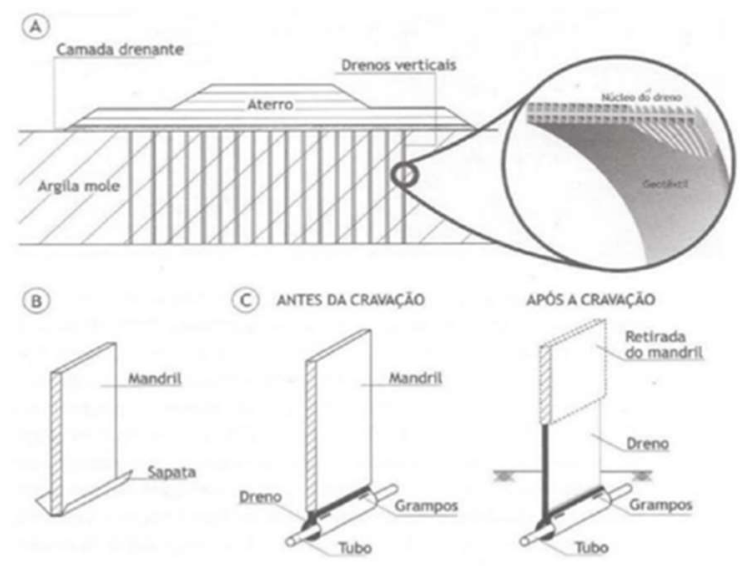

Figura 2: Representação de aterro com drenos verticais

Como podemos observar a distância de drenagem é diminuída e havendo uma predominância de dissipação do excesso de poro pressão no sentido horizontal-radial e fazendo com que a drenagem vertical tenha menor importância o que acaba por acelerar o adensamento (Departamento de Estruturas e Fundações - UERJ).

Sobre esse método, os geodrenos se destacam em função da sua resistência as alterações do solo e ao método de cravação dos mesmos. Vale lembrar que para cravar os drenos é importante que isso seja feito por maneira hidráulica visto que outros métodos poderiam afetar o solo sobre o qual serão inseridos os drenos o que prejudicaria a sua função (NASCIMENTO, 2008).

\section{DISCUSSÃO TEÓRICA}

\section{Estudos dos Cortes}

A partir dos ensaios de sondagem a percussão é possível analisar a estratigrafia do terreno, após esse processo é necessário realizar ser elaborado um plano de sondagem para o DNIT (2015), este plano deve ser elaborado para servir como suporte nas investigações do subleito, para estudo da estabilidade dos taludes e para classificar os materiais de corte, possibilitando que os furos no processo de sondagem possam ser 
racionalizados, fazendo uma análise geológica de trecho para que possa coletar dados geotécnicos e geofísicos na hora de se inspecionar o campo.

\section{Análise da Estratigrafia do Terreno}

Para Teixeira et al. (2015), em solos moles há a necessidade de um reconhecimento adequado da estrutura do subsolo e das propriedades geotécnicas dos materiais utilizados, essas informações são adquiridas em ensaio de sondagem a percussão e sondagem mista.

\section{Sondagem a Percussão}

De acordo com a NBR 8036 (1983), a sondagem a percussão ela fornece dados pra principais investigações do subsolo, variando de acordo com obra e os tipos de carregamentos, a estrutura e as condições geotécnicas de onde está sendo estudada. Essa sondagem foi a utilizada no projeto, o resultado do NSPT atingiu 25 golpes com $6 \mathrm{~m}$ de profundidade, está foi utilizada pois de acordo com está norma, a sondagem a percussão atingi as camadas improprias do terreno, onde o solo não seja, mas considerado solicitado pelas cargas estruturais.

\section{Alternativas construtivas para a fundação}

Uma alternativa seria a substituição do solo mole por um material mais resistente. Primeiramente seria retirada as camadas do solo que são mais moles e possuem um baixo NSPT. Posteriormente seriam substituídas por um material com melhores características. Mas deve se tomar certos cuidados coma a implantação dessa técnica de acordo com Almeida (2010), os equipamentos devem ser leves, realizando a escavação por parcelas, o que pode tornar o processo bastante demorado exigindo que se planeje a entrada e saída de material do canteiro. A Figura 3 demostra quando não há planejamento desse tipo de escavação quais danos podem causar.

Outra alternativa seria o aterro normal. Para realizar esse procedimento, porém, é necessário verificar quanto o solo iria sofrer com recalque, dessa forma é colocado mais material necessário para fazer o aterro até o nível desejado, já considerando o recalque, de forma que com o recalque ele atinja a altura desejada.

Também é possível utilizar o aterro sobre estacas com a ajuda de geogrelha. Esse procedimento é eficaz, pois as cargas do aterro são transferidas para as estacas com o auxílio da camada de geogrelha, ou seja, não dependendo do solo mole. As estacas, por sua vez, vão transmitir os esforços para as camadas mais profundas e resistentes do solo.

$\mathrm{O}$ aterro com geogrelha seria uma das técnicas mais adequadas para reforço entre as duas linhas ferroviárias, para Nascimento (2008), essa técnica é bastante utilizada quando há implantação de novas ferrovias ou duplicação das mesmas, com a finalidade de reduzir os recalques construtivos que podem gerar a instabilidade do material rodante. 


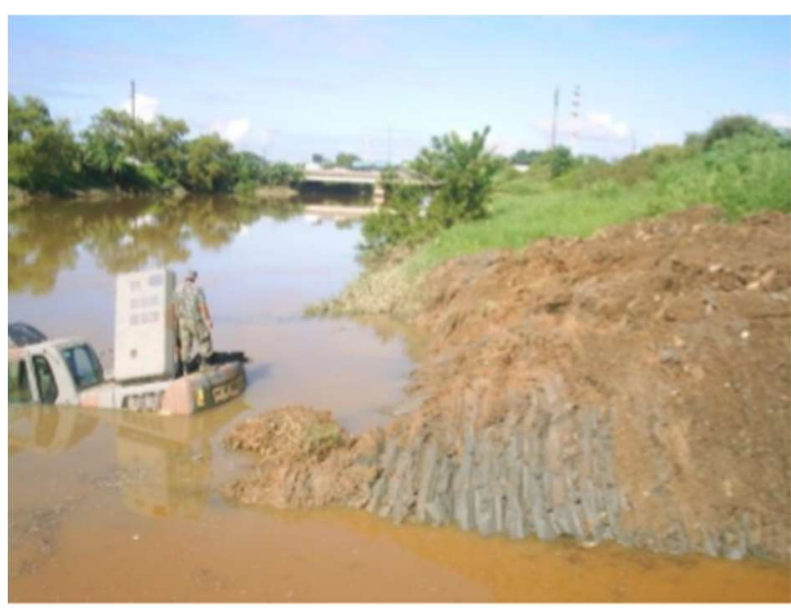

Figura 3: Acidente envolvendo escavação de solo mole. Fonte: Carvalhais (2017).

\section{CONCLUSÕES}

Portanto, é possível observar a importância do estudo prévio sobre as condições do solo antes de qualquer procedimento que seja feito sobre o mesmo. Remediar essas situações após o aparecimento de possíveis defeitos em geral custa um maior prejuízo econômico do que o custo para um estudo do solo antes de ser iniciada a construção.

Sendo assim, uma vez que é verificado que determinado solo possui uma característica compressível e que previsivelmente com o auxílio de estudos é constatado que se trata de um solo mole, é de extrema importância a busca por meios de sanar essa problemática antes do aparecimento dos seus efeitos sobre a edificação.

Nesse contexto foram apresentadas algumas alternativas eficazes de acordo com as situações propostas. Retirada do material mole e substituição por um material de qualidade, sobrecarga temporária e drenos verticais são algumas das diversas alternativas cabíveis e viáveis para resolver essa problemática. Adotar essas medidas contribui para o zelo da economia e da segurança das ferrovias estudadas.

\section{REFERÊNCIAS}

ALMEIDA, M. S. S; MARQUES, M. E. S.. Aterros sobre solos moles projeto e desempenho. São Paulo: Oficina de Textos 2010.

ARTERIS, C. D. T.. Aterro sobre solos compressíveis. 15 ed. Arteris, 2015.

CAPUTO, H. P.. Mecânica dos solos e suas aplicações. 6 ed. São Paulo: LTC, 1988.

CIRONE, A.; ODEBRECHT, E.; DOMINGUES, G.; RODRIGUES, J. C.; CAVILHA, R. L.. Execução Jet Grouting se destaca na construção da linha de $\mathbf{5}$ do metrô. Rudder, 2017.

CARVALHAIS, R. F.. Comportamento geotécnico de aterros aeroportuários sobre fundações compressíveis: Estudos e análises do aterro do aeroporto de Itajubá/MG. Dissertação (Mestrado) - Universidade Federal de Ouro Preto, Ouro Preto, 2017.

DNIT. Departamento Nacional de Infraestrutura de Transportes. ISF-207: Estudos Geotécnicos. Manual de
Instrução do Serviço Ferroviário. São Luís: DNIT, 2015.

GAUI FILHO, R.. Obras sobre solos moles e suas respectivas soluções: um exemplo prático da obra de um Complexo de Vacinas em Santa Cruz, RJ. Rio de Janeiro: UFRJ, 2017.

LEMOS, S. G. F. P.. Estudo da resistência não drenada do solo de baixa consistência por meio de ensaios de campo e laboratório. Dissertação (Mestrado) - Universidade Federal do Espirito Santo, Vitória, 2014.

MACHADO, L. V. S. S.. Avaliação do deslocamento vertical de aterro sobre solo mole executado no projeto de duplicação da BR-101/PE. Dissertação (Mestrado) Universidade Federal de Pernambuco, Recife, 2012.

MARANGON, M.. Mecânica dos Solos II. Faculdade de Engenharia, 2018.

MORAIS, E. R.. Avaliação de índices físicos, mecânicos e estruturas do solo, aplicado a pavimentação. Revista Vetor, Rio Grande, v.25, n.2, 2015. 
NASCIMENTO, C. M.. Avaliação de alternativas de processos construtivos de ferrovias sobre solos moles. Monografia (Especialização) - Instituto Militar de Engenharia, Rio de Janeiro, 2008

NOGUEIRA, E. G.. Estudo de algumas soluções de tratamento de solos moles para a construção de aterros no trecho Sul do Rodoanel/SP. Dissertação (Mestrado) - Escola
Politécnica da Universidade de São Paulo, São Paulo, 2010.

SOUSA, P. M. L. S.. Limite de liquidez: correlações e comparações entre os métodos de fall cone e da concha casa grande. Dissertação (Mestrado) - Universidade de Nova Lisboa, Lisboa, 2011.

TEIXEIRA, C. C.; MAS, P.. Análise da estabilidade de aterros de solo moles. Universidade Extremo Sul Catarinense, 2015.

A CBPC - Companhia Brasileira de Produção Científica (CNPJ: 11.221.422/0001-03) detém os direitos materiais desta publicação. Os direitos referem-se à publicação do trabalho em qualquer parte do mundo, incluindo os direitos às renovações, expansões e disseminações da contribuição, bem como outros direitos subsidiários. Todos os trabalhos publicados eletronicamente poderão posteriormente ser publicados em coletâneas impressas sob coordenação da Sustenere Publishing, da Companhia Brasileira de Produção Científica e seus parceiros autorizados. Os (as) autores (as) preservam os direitos autorais, mas não têm permissão para a publicação da contribuição em outro meio, impresso ou digital, em português ou em tradução. 